\title{
Gender Identity Construction in Facebook Statuses of Egyptian Young Adults
}

Ingy Emara*

The past few years have witnessed a remarkable increase in computer-mediated communication (CMC), a fairly recent genre of which is online social networking. Online social networking sites allow users to engage in computermediated communication with a large network of friends and family. Social networking sites are defined by Boyd and Ellison (2007) as web-based services allowing users to construct a public profile within a specific system, share connections with other users and both view and review their list of connections and those made by other users within the system.

One of the most popular social networking sites nowadays is Facebook which has become a popular way of communicating ideas and expressing one's views. Facebook was created by Harvard University student, Mark Zuckerberg in 2004 and was made available to everyone using the World Wide Web by the end of 2006. Ever since 2006, Facebook has become one of the fastest growing and most popular online social networks. A Facebook status allows users to post information or express certain views, and it provides opportunities to friends to comment on what is posted or simply to like and sometimes share their friends' status updates. As such, it also serves the function of constructing one's identity through status posts.

Identity is conveyed through language and through the way one interacts with others. It is characterized in terms of one's personality traits, values, beliefs, roles and relationships (Huffaker \& Calvert, 2006). The construction of identity also refers to the construction of self as one that involves the construction of several public selves which are presented in accordance with cultural and social constraints (Harter, 1998). As such, identity is clearly influenced by the role of an individual as a member of a particular gender. Gender identity is socially constructed through a set of behaviors and perceptions that define what it means to be a woman and what it means to be a man (Lemish, 2008). However, the construction of one's identity in face-to-face communication may differ from identity construction in online settings in several ways.

In face-to-face communication, views and emotions are expressed both linguistically through the language patterns used in verbal utterances and

\footnotetext{
*Faculty of Al-Alson and Mass Communicaiton, Misr International University.
} 
paralinguistically through non-verbal features such as facial expressions, gestures, intonation and voice pitch (Park, 2007). However, this is not the case in online communication where views and emotions can only be expressed through the use of verbal language and certain emoticons or text-based representations of feelings. Yet, even with the use of emoticons, a person's view may be misunderstood as it has been found that people may perceive emoticons differently and that different genders may also interpret the meaning of emoticons differently (Hudson, Nicolas, Howser, Lipsett, Robinson, Pope, Hobby \& Friedman, 2015). The online communicator, therefore, may be under more pressure when choosing the language patterns that would most accurately express his/her views and attitudes. This, in turn, highlights the importance of analyzing online communication in order to investigate the linguistic patterns each gender prefers to use to express different views and emotions.

The present research paper investigates ways in which young Egyptian adults construct their identities on Facebook status posts. It also examines how the online linguistic behavior of male Facebook users may be different from female ones under the premise that there are gender differences in the way men and women represent themselves in language (Lakoff, 1975; Tannen, 1990). In this regard, the paper aims to test two hypotheses. The first hypothesis claims that men post more about facts, entertainment and individual experiences, while women post more about feelings, social relationships and activities involving others, which is supported by Tannen (1990). The second hypothesis maintains that men use language showing authority and assertiveness, while women's language shows uncertainty and tentativeness, a view that is adopted by Lakoff (1975). In order to test these two hypotheses, the following research questions are investigated:

1. What are the topics discussed in Egyptian males' and females' Facebook status posts?

2. What are the linguistic stance features and engagement strategies used by each gender to express particular attitudes?

The answers to the above research questions as well as the validation or refutation of the set hypotheses shed light on the linguistic patterns that Egyptian Facebook users choose to construct their gender identities on online social networks, and the social and cultural implications these linguistic patterns may have.

\section{Literature Review}

Due to the growing popularity of Facebook, several researchers have studied the implications of Facebook communication on aspects of identity such as self presentation (Fogel \& Nehmad, 2009; Kramer \& Winter, 2008; Tong, Van Der 
Heide, Langwell \& Walther, 2008) and socio-cultural attitudes (De Andrea, Shaw \& Levine, 2009). With the rising popularity of Facebook as a social networking site, a new area of research is being conducted to study the relationship between gender and computer-mediated communication and to examine whether established trends in language and gender research can be reproduced in an online environment (Weatherall, 2008).

Gender, unlike sex, seems to be a continuous variable (Graddol \& Swann, 1989). Identities are not fixed but continually reshaped by cultural performances, which implies that gender is reaffirmed and publicly displayed by performing particular acts in accordance with cultural and societal norms (Butler, 1990). It is commonly believed that culture is not gender-neutral as all cultures set up social norms for the sexes which go beyond biological differences, even though cultures may differ in the traits they assign to both men and women (Lury, 1995). Language is one realm that is shaped by the way an individual acts as a man or a woman and that reproduces an individual's definition of cultural identity (Burman \& Parker, 1993).

Most of the literature on language gender differences concentrates on two main theories: the dominance approach and the difference approach. The dominance approach is supported by Robin Lakoff (1975) and claims that gender differences arise from male dominance and female subordination. Lakoff suggests that women's subordinate social status is indicated by the language they use. She identified a number of linguistic features which she claims are used more often by women than by men and which expressed uncertainty and lack of confidence. These features include lexical hedges or fillers, tag questions, empty adjectives, intensifiers, superpolite forms, euphemism and emphatic stress (Lakoff, 1975). The difference approach, on the other hand, is supported by Deborah Tannen (1990) and maintains that gender differences are related to cultural differences between men and women. According to Tannen (1990), women tend to use language for intimacy or 'rapport talk', while men tend to use it for information or 'report talk'.

A large body of previous research agreed with the above mentioned theories as men were found to be more assertive, independent, individual, informative and unemotional, while women were more vulnerable, uncertain, emotionally expressive and concerned for the welfare of others (Bond, 2009; Eagly, 1987; Lemish, 2008; Walker, 2015). Due to social influences in face-to-face settings, men were found to be more associated with action, adventure and competition while women tended to be more concerned with the welfare of others, emotionally expressive, open, dependant and vulnerable (Lemish, 2008). This implies that women's communication indicates a desire for solidarity and maintaining social relationships while men's communication indicates a desire 
for power and instrumental purposes such as disseminating information rather than building personal relationships (Lemish, 2008 and Bond, 2009).

One explanation for gender differences in language is the social context theory (Deaux \& Major, 1987) which focuses on social rather than individual factors. For example, a contextual influence is males' greater status in society, which makes them more likely to dominate social interactions through the use of self-assertive language, whereas females tend to behave subordinately through using more affiliative language. Another aspect of contextual influence is the activity setting, which maintains that the different activities the two genders engage in have different associated language patterns. For example, females engage in more self-disclosure tasks which require affiliative language while men engage in task-oriented activities requiring more assertive language (Deaux \& Major, 1987).

In today's world, gendered communication patterns have taken new forms with the rising popularity of the World Wide Web and online social networks. Electronic communication is becoming more popular among people of different genders and ages as it has blurred the boundaries of spoken and written communication as well as the distinction between formal and informal language (Naughton, 1999). Online language is now considered a new type of discourse that is shaped by the creativity and innovation of its users (Crystal, 2001). It has therefore become essential to study gender differences in online communication settings in order to investigate similarities and differences between online and offline gender identities.

Gender differences in face-to-face communication were found to be mirrored in online communication where women tended to communicate in more emotional interpersonal ways, while men tended to communicate in more taskoriented individual ways (Weatherall, 2008 and Parkins, 2012). Research findings suggest that women's online behavior is more interpersonally-oriented showing interaction and relationship maintenance, while men's online behavior is more individual and information-oriented (Parkins, 2012).

In terms of politeness strategies, male and female online linguistic behavior was found to be similar to face-to-face interactions. Savicki (1996) found that in online discussion groups, females tended to self-disclose and avoid tension while men tended to use impersonal, fact-oriented language. Moreover, women were more likely to use politeness strategies to thank, appreciate and apologize and were more likely to be upset by violations of politeness, whereas men seemed less concerned with politeness and more likely to violate expected conduct (Herring, 2000). In another study made by Arnold and Miller (1999) to analyze the language used in personal web pages, women were found to be more sociable and friendly while men portrayed themselves as confident and independent. 
Recently, there has been a rising interest in gendered communication patterns on social network sites, especially Facebook, and how they may be similar or different from face-to-face communication patterns. Most research conducted in this area has found that communication on social network sites mirrors face-toface communication to a considerable extent. For example, men tended to use social network sites to form new relationships while women tended to use social network sites to maintain existing relationships (Muscanell \& Guadagno, 2012). While using social network sites, females tended to disclose more about social relationships with others and settings of social gatherings such as holidays and parties, whereas men tended to disclose more information relating to entertainment such as sports (Bond, 2009).

In relation to the use of emotional language, Thelwall, Wilkinson \& Uppal (2009) found that female comments on Facebook contained more positive emotion words than male comments, but the two genders did not show differences in terms of negative emotion language. Also females were found to be more likely to use affiliative language to connect with others, whereas males used assertive language to show dominance and goal achievement (Thelwall et al., 2009). In another study conducted by Joiner, Dapkeviciute, Johnson, Gavin \& Brosnan (2015), it was found that females showed higher levels of emotional support to Facebook status updates from friends both in private and public replies whereas males showed more emotional support in private replies than public replies. This supports the finding that the two genders are more likely to behave in stereotypical ways in front of larger groups of people (Deaux \& Major, 1987).

In terms of identity construction, Facebook posts can reveal several aspects of an individual's identity. While social networking sites allow users to engage in computer-mediated communication with a large network of friends and family, they also provide them with ways to formulate particular online identities (Lee 2008). Identity is characterized in terms of one's personality traits, values, beliefs, roles and relationships (Huffaker \& Calvert, 2006). The construction of identity is greatly shaped by cultural and social constraints (Harter, 1998), and as such, identity is clearly influenced by the role of an individual as a member of a particular gender. Gender identity refers to a person's sense of self as a member of a particular gender and is greatly shaped by socially accepted standards of femininity and masculinity (Parkins, 2012).

Gender identity can be constructed in both online and face-to-face communication. An online identity is influenced by a sense of freedom from physical constraints as well as more ability to design one's persona (Turkle, 1995). Bolander \& Locher (2010) have shown that status Facebook updates tend to provide rather indirect information on the users' self concepts and group 
affiliations. Similarly, Eisenlauer (2013) has found that Facebook users utilize text automation properties in order to mitigate their discursive acts of selfpositioning. Unlike self-authored texts which run the risk of being interpreted as rather straightforward and blunt identity performances, the use of softwaregenerated text, such as those posted in status updates, allows Facebook users to claim various identity aspects in more indirect ways (Eisenlauer, 2013). The present paper aims to examine whether the implications of the above findings are also applicable to the construction of online gender identity.

Although there has been a rising interest in the analysis of online communication patterns, researchers believe that more studies are needed to investigate social networking communication such as Facebook in relation to gender (Thompson \& Lougheed, 2012). Also, most of the studies conducted in this area are related to western communities rather than eastern and Arab communities. Therefore, this present study aims to fill in this gap by extending literature on gender differences in social network communication in the Egyptian society. The study also aims to examine how young Egyptian adults construct their gender identity on the most popular social network site, Facebook, and how far their identity construction conforms to the results of previous research and gender-related linguistic theories.

\section{Methodology}

The present research paper investigates ways in which young Egyptian adults construct their identities on Facebook status posts. It also examines how the online linguistic behavior of male Facebook users may be different from female ones under the premise that there are gender differences in the way men and women represent themselves in language (Lakoff 1975; Tannen 1990). The research adopts a quantitative-qualitative analysis where collected Facebook status samples are examined in terms of the frequency of occurrence of certain gender-related parameters posited by Lakoff (1975) and Tannen (1990), and the implication such parameters may have on the representation of one's identity.

The samples analyzed in this study are 100 Facebook statuses posted in the first quarter of the year 2016 by 50 males and 50 females (one status post is chosen for each male or female user.) The subjects chosen are Egyptian Facebook users aged between 20 and 30 years as social networking is believed to be more popular among young adults (Hargittai 2008). They all belong to the upper-middle class and have a minimum of a Bachelor's degree. They are all graduates of private universities in Egypt and most of them have good command of English. This population is chosen as it represents Facebook users who are able to express their views openly using correct English language. The posts are written in English, and the average length of each post is 37 words for male posts 
and 40 for female ones. They are about general topics, usually situations that the Facebook users experienced or comments about social issues. The posts are selected according to their length and the language they are written in; i.e. English. In most cases, the Facebook post chosen for each user is the only English text of the average length of 40 words posted on the user's wall in the chosen period. Most of the other posts are either too short or written in Arabic or Franco-Arabic, which is the English alphabet used to communicate in Arabic over social media channels. The researcher chose statuses written in English in order to facilitate the analysis of linguistic elements in accordance with the gender-related linguistic theories of Lakoff (1975) and Tannen (1990), and to make it possible to compare the results of the present study to the results of previous studies conducted on English data.

The choice of English in writing a status shapes part of the user's identity as a bilingual speaker. It also implies that the user expects the status to be read by friends of different nationalities, or that he/she wants it to be read by a selected audience that can understand English. The choice of a second language in this case may give Facebook users the opportunity to present themselves in a way that will be more appealing to the audience they want to communicate with. Some researchers have found that the use of a second language and the withdrawal from the first language may not only be an act of rebellion against local norms, but it may also be an attempt to socialize into recognized second language identities (Klimanova, 2013). Thus, the analysis of English posts in this study serves the function of investigating the users' identity in a more general setting that is free from any socio-cultural linguistic boundaries that may be posed by their first language.

The subjects were chosen based on a convenience sampling method as they were drawn from a specific population of users in the researcher's list of Facebook friends, and permission was granted to linguistically analyze the Facebook statuses they posted during the first quarter of the year 2016. The researcher chose users on her friend list and not random users that she does not know in order to be certain about the gender of each user, as some Facebook users tend to assume virtual online genders that are different from their real ones (Huffaker \& Calvert, 2006). The data was collected after the users had already posted their statuses without prior knowledge that these statuses would be analyzed for research purposes so there was no chance that the data collected was purposely skewed in any way.

The present study applies a quantitative-qualitative content analysis of the selected Facebook posts. This type of analysis tackles the themes the discourse is developed around and investigates the selection of relevant linguistic elements, the frequency of occurrence of each and the relationships between the 
different elements (Ruiz, 2009). The selected status posts were analyzed in terms of the frequency of occurrence as well as the relevance of the linguistic devices used to refer to the status topic and to the writer's stance and the implications of the writer's choice of language on identity construction.

Based on the findings of previous research studies which have been mentioned in the literature review section above, the present paper aims to test two hypotheses. The first hypothesis claims that men post more about facts, entertainment and individual experiences, while women post more about feelings, social relationships and activities involving others. The second hypothesis maintains that men use language showing authority and assertiveness, while women's language shows tentativeness. In order to test these two hypotheses, the following research questions are investigated:

1. What are the topics discussed in Egyptian males' and females' Facebook status posts?

2. What are the linguistic stance features and engagement strategies used by each gender to express particular attitudes?

In order to test the above-mentioned hypotheses and address the set research questions, the linguistic analysis of the selected posts tackles three linguistic choices: choice of topic, affiliative and affective lexical choices, and stance features and engagement strategies expressing personal attitudes. A broad theoretical and empirical literature suggests that the relationship between language and gender can be characterized in terms of situated meanings which construct gender through the use of stances, styles and persona (Eckert, 2008). The content analysis of the above-mentioned linguistic choices aims to portray the linguistic patterns that Egyptian Facebook users choose to construct their gender identities on online social networks, and the social and cultural implications these linguistic patterns may have.

\section{Results and Discussion}

This section presents the results of the linguistic content analysis of the selected Facebook status posts in terms of choice of topic, affiliative and affective lexical choices, and stance features and engagement strategies expressing personal attitudes.

\section{Choice of Topic}

The topics discussed in the 100 selected Facebook status posts could be grouped into three main topics: social relationships and experiences, personal experiences and expressing opinion and/or giving advice. The following table shows the 
number and percentage of males and females choosing each topic and the statistical significance of the difference between the two groups.

Table 1

Choice of topic made by males and females

\begin{tabular}{|l|l|l|l|l|l|}
\hline Topic chosen & $\begin{array}{l}\text { Number } \\
\text { of Male } \\
\text { posts } \\
\mathrm{N}=50\end{array}$ & $\begin{array}{l}\text { Percentage } \\
\text { of male } \\
\text { posts }\end{array}$ & $\begin{array}{l}\text { Number } \\
\text { of Female } \\
\text { posts } \\
\text { N=50 }\end{array}$ & $\begin{array}{l}\text { Percentage } \\
\text { of female } \\
\text { posts }\end{array}$ & $\begin{array}{l}\text { Significance/ } \\
(2 \text { tailed) P } \\
\text { value }\end{array}$ \\
\hline $\begin{array}{l}\text { Social } \\
\text { relationships } \\
\text { and } \\
\text { experiences }\end{array}$ & 8 & $16 \%$ & 30 & $60 \%$ & $*<0.0001$ \\
\hline $\begin{array}{l}\text { Personal } \\
\text { experiences } \\
\text { (not involving } \\
\text { others) }\end{array}$ & 24 & $48 \%$ & 7 & $14 \%$ & $* 0.0002$ \\
\hline $\begin{array}{l}\text { Opinion/ } \\
\text { Advice }\end{array}$ & 18 & $36 \%$ & 13 & $26 \%$ & 0.2843 \\
\hline
\end{tabular}

The $\left(^{*}\right)$ refers to $p$-values that are highly significant where $p<0.05$

The above table shows that a significantly larger number of females choose to discuss topics related to social relationships and experiences $(60 \%$ of the females compared to $16 \%$ of the males with a $\mathrm{p}$ value less than 0.0001 suggesting that the difference is extremely statistically significant). On the other hand, a significantly larger number of males choose to discuss personal experiences not involving others (48\% compared to $14 \%$ with a $p$ value of 0.0002 suggesting an extremely statistically significant difference). The topics related to social experiences in female posts are mainly about showing gratitude to friends and family, stressing the importance of love between couples or friends and relatives, and complaining about negative social practices such as interference in people's lives. This implies that females are more concerned with maintaining social relationships and showing intimacy to others while at the same time paying heed to social norms and pressure. On the other hand, the topics that males post about social experiences include obituaries to a dead pet or person, expressing gratitude to friends and criticizing others' practices. None of the male posts studied discusses romantic relationships, which implies that the Egyptian male users do not like discussing their personal relationships with their female partners (e.g. spouse, fiancée or girlfriend) in public. The above findings support the first hypothesis that women are more concerned with social relationships and 
show that women tend to talk more about emotional experiences and feelings towards others.

As for personal experiences, the females discuss topics such as complaining about negative experiences they have had with a certain service, sharing experiences of donating to charity organizations and sharing sad emotions about being lonely. Males, on the other hand, boast about personal choices such as drinking beer, forcing others to respect them and having freedom to do anything they like. The females' choices of personal experiences reflect their tendency to show feelings, intimacy, and understanding, while the males' choices reflect their tendency to show power, independence, status and conflict, which all agrees with Tannen's model of male and female contrasts (Tannen, 1990).

In terms of giving advice, though more males give advice in their posts than females do, the difference is not statistically significant as the $\mathrm{p}$ value is higher than 0.05 , i.e. 0.2843 . However, the topics of advice differ among male and female Facebook users. The advice given by females is mainly related to how to maintain healthy relationships among friends or couples as in "Never get upset from people who always give you negative comments" and "Have a kind heart and mind; forgive and forget; live in peace and make this life a better place", which also shows willingness to compromise. On the other hand, the advice given by males is mainly to encourage others to enjoy life by practicing sports and travelling, to forget about all political and social problems and to stick to one's point of view as in "Stop worrying and live your life," and "Dream big and follow your heart." This finding agrees with Tannen's contrast model maintaining that women tend to seek compromise while men prefer to show conflict and independence of choice (Tannen, 1990).

The above findings also address the first research question examining the topics chosen by each gender, and they reveal that females show more tendency to discuss social relationships and experiences, while males prefer to discuss topics related to personal experiences and expressing opinion that stresses independence and power. The topics frequently discussed by male users are mainly about personal experiences and activities such as sports, entertainment, alcohol, travelling and politics, while women mainly discuss activities shared with others and refer to emotional experiences, especially those involving love and happiness.

The same findings support the first hypothesis posed in this research which claims that men post more about facts, entertainment and individual experiences, while women post more about feelings, social relationships and activities involving others. Facts in men's statuses are found in posts expressing opinion and giving advice which have a highly referential or informative function, while entertainment and individual experiences are found in posts about personal 
experiences which mainly revolve around adventurous entertainment practices or individual work experiences. The females' posts studied are mostly concerned with social relationships and experiences represented by activities involving others such as parties, celebrations and outings.

\section{Affiliative and affective lexical choices}

Affiliative lexical choices refer to language that affirms and joins with the other person (Foster, 2004) whereas affective lexical choices refer to language that signifies the speaker's or writer's feelings, moods, dispositions and attitudes (Besnier, 1990).

\subsection{Affiliative lexical choices}

The affiliative lexical choices analyzed in the selected status posts refer to words signifying social relations such as friend, father, mother, spouse, etc. Table 2 shows the number and percentage of males and females using each of the eight lexical terms describing social relations in the posted statuses. The number of females mentioning social relations in their statuses is 29 out of $50(58 \%)$, while the number of males mentioning social relations is 14 out of $50(28 \%)$.

Table 2 Social relations in the statuses posted by each gender

\begin{tabular}{|l|l|l|l|l|}
\hline $\begin{array}{l}\text { Social } \\
\text { relationship }\end{array}$ & $\begin{array}{l}\text { Number of } \\
\text { males } \\
\mathrm{N}=14\end{array}$ & $\begin{array}{l}\text { Percentage of } \\
\text { males } \\
\mathrm{N}=14\end{array}$ & $\begin{array}{l}\text { Number of } \\
\text { females } \\
\mathrm{N}=29\end{array}$ & $\begin{array}{l}\text { Percentage of } \\
\text { females } \\
\mathrm{N}=29\end{array}$ \\
\hline Friend(s) & 7 & $50 \%$ & 12 & $41.5 \%$ \\
\hline Father & 2 & $14.5 \%$ & 1 & $3.5 \%$ \\
\hline Mother & 0 & $0 \%$ & 1 & $3.5 \%$ \\
\hline Both parents & 2 & $14.5 \%$ & 0 & 0 \\
\hline Brother & 1 & $7 \%$ & 3 & $10 \%$ \\
\hline Sister & 0 & $0 \%$ & 7 & $24 \%$ \\
\hline Spouse & 0 & $0 \%$ & 2 & $7 \%$ \\
\hline Relative(s) & 1 & $7 \%$ & 1 & $3.5 \%$ \\
\hline Child & 1 & $7 \%$ & 2 & $7 \%$ \\
\hline
\end{tabular}

Table 2 shows that females, in general, have more tendency than males to refer to social relations with others. The number of females mentioning social relations is more than double that of males; $29(58 \%)$ of the females compared to $14(28 \%)$ of the males mentioned social relationships in their posts. It was only in cases of reference to the father or both parents that the males 
outnumbered the females. These findings support the first hypothesis maintaining that women post more about social relationships and activities involving others. Another finding that can be obtained from Table 2 is that none of the males in the sample makes any reference to female relations such as mother, sister and spouse, which implies that Egyptian men do not prefer to discuss relationships with female family members in public. This is supported by previous research which found that men in Arab countries refuse to mention female relatives such as mothers, sisters, daughters and wives as they consider this a matter of protection even though it implies marginalization of women's role in society (Shalghin, 2017).

\subsection{Affective lexical choices}

The affective lexical choices examined in this study refer to words signifying feelings or emotions towards a specific person or issue. The researcher counted only the instances where the Facebook users under study referred directly to their emotions towards something or someone. There were six basic emotions mentioned in the collected samples: love, happiness, worry, sadness, hatred and anger. Examples of sentences showing the fore-mentioned emotions are: "I love when two people get back together" (love), "I'm so happy today" (happiness), "I'm worried about kids" (worry), "I feel sad that we force ourselves into the act of being hurt" (sadness), "I hate Real Madrid" (hate), and "I'm filled with anger" (anger). The number of females using words expressing their emotions is more than double that of males as $41(82 \%)$ of the females used affective words compared to $17(34 \%)$ of the males. The following table shows the number of males and females using affective words related to the above-mentioned six emotions in the posted statuses and the statistical significance of the difference between the two groups.

Table 3 Number of males and females using affective words referring to each emotion.

\begin{tabular}{|l|l|l|l|}
\hline $\begin{array}{l}\text { Emotion } \\
\text { expressed }\end{array}$ & $\begin{array}{l}\text { Number of males using } \\
\text { affective } \\
\text { referring to each } \\
\text { emotion. }\end{array}$ & $\begin{array}{l}\text { Number of females } \\
\text { using affective words } \\
\text { referring to each } \\
\text { emotion. }\end{array}$ & $\begin{array}{l}\text { Significance/ (2 } \\
\text { tailed) P value }\end{array}$ \\
\hline Love & 4 & 17 & $* 0.0012$ \\
\hline Happiness & 3 & 13 & $* 0.0060$ \\
\hline Worry & 3 & 2 & 0.6503 \\
\hline Sadness & 0 & 7 & $* 0.0057$ \\
\hline Hatred & 2 & 0 & 0.1562 \\
\hline Anger & 5 & 2 & 0.2440 \\
\hline
\end{tabular}

The $(*)$ refers to $p$-values that are highly significant where $p<0.05$ 
The above findings show that the difference between the two groups in expressing the emotions of love, happiness and sadness is very statistically significant $(0.0012,0.0060$ and 0.0057 respectively) while the two genders do not differ significantly in expressing the emotions of worry, hatred and anger, possibly due to the small number of users making reference to the three latter emotions. Females tend to discuss their emotions more directly than males do, especially in relation to positive emotions such as love and happiness. A significantly larger number of females refer to emotion of love when talking about spouse, family or friends as in, "I love when two people get back together after a long time," and "Thank you for the party, my dear friends. Love you all." However, only 4 males mention words related to love, and it is love for beer, for a deceased pet or person, or for nephews that is mentioned in the males' posts as in, "If I had children of my own, I wouldn't love them as much as I love you both." None of the males mentions love relations with the other gender, nor does any of them mention love for friends. This suggests that women are more concerned with emotions, maintaining healthy social relationships and complimenting others while men are more concerned with showing status and power.

Table 3 above also shows that females make a significantly larger number of references to the emotion of happiness than men do. Examples of female posts showing happiness include "My only goal in life right now is to be happy," and "It's not about being engaged, married or in any relationship; it's about being secured, happy, safe, relieved and feeling good." Examples of men's posts showing happiness include "I'm glad [my father] that you taught me so well," and "I'm glad to have you around, my friends." It is worth mentioning however that all the females refer to the emotion of happiness using the word "happy" while the three males who refer to happiness in their posts use the word "glad" rather than "happy" to describe their state of mind. According to the American Heritage Dictionary of the English Language, "glad" refers to the emotion resulting from the satisfaction of a certain need and describes a temporary state of pleasure, whereas "happy" refers to the feeling of permanent pleasure or satisfaction. This implies that women tend to value long-lasting feelings of happiness and satisfaction and to express them directly more than men do.

The above findings agree with previous research which found that female comments on Facebook contain more positive emotion words than male comments (Thelwall et al., 2009). It has also been found that emotions of happiness and sadness are more characteristic of women, whereas men are believed to be more characteristically angry (Kelly \& Hutson-Comeaux, 1999), which is reflected in the above results showing that women express feelings of love, happiness and sadness more than men do. Table 3 above also shows that 
more men than women refer to the feeling of anger in their posts, though the difference is not statistically significant due to the small number of comments referring to the feeling of anger. Females in the present study are also more likely to discuss feelings of sadness while none of the males mentions any sad emotion, which implies that men view the expression of such emotions as a sign of weakness. The above findings also support the hypothesis that women post more about feelings in their Facebook statuses.

\section{Stance features and engagement strategies}

The stance features and engagement strategies discussed here refer to how each Facebook user referred to the self and others, how he/she used hedging devices to show tentativeness or uncertainty and boosting devices to show emphasis, and how each of them used adjectives and adverbs as attitude markers. Hyland (2005) proposes a model that describes the notion of self-representation and engagement with others based on certain stance features and engagement strategies. He maintains that one way writers choose to represent themselves in a text is through the use of stance strategies such as self mentions (I, we, my), hedges (might, perhaps), boosters (definitely, so much) and attitude markers such as adjectives and adverbs expressing their attitude toward a certain proposition. In terms of engagement strategies, writers can engage themselves with the readers through the use of reader pronouns (we, us) and reader-targeting directives such as imperative statements and questions (Hyland, 2005).

The present study attempts to apply Hyland's model to investigate stance features and engagement strategies through the analysis of five linguistic features: pronouns to examine the implications of reference to the self and others, hedging devices to investigate the writer's mitigation of sentence force, boosting devices to investigate the writer's sense of assertion, and both adjectives and adverbs used to express his/her attitude towards a certain proposition.

\subsection{Pronouns}

The present study investigates the subjects' use of pronouns as they highlight factors such as proximity or distance and directness or indirectness between the writer and reader (Fowler, Hodge, Kress \& Trew, 1979). For example, the use of the pronoun we may indicate intimacy and solidarity between the writer and the reader, whereas the generalized you can sometimes refer to anyone and may imply that the individual addressed is different from the writer. The pronouns analyzed here are the pronouns which have been used in the selected status posts. The following table shows the word count and lexical density (shown by percentage) of each type of pronouns in the posts of each gender. The total 
number of words in the male posts is 1835 , and the total number of words in female posts is 2018 .

Table 4 Word count of pronouns in statuses of both genders

\begin{tabular}{|l|l|l|l|l|}
\hline Pronoun & $\begin{array}{l}\text { Word Count in } \\
\text { Male Posts } \\
\mathrm{N}=1835\end{array}$ & Percentage & $\begin{array}{l}\text { Word Count in } \\
\text { Female Posts } \\
\mathrm{N}=2018\end{array}$ & Percentage \\
\hline $\begin{array}{l}\text { First person } \\
\text { singular (I, } \\
\text { me, my) }\end{array}$ & 118 & $6.43 \%$ & 105 & $5.20 \%$ \\
\hline $\begin{array}{l}\text { First person } \\
\text { plural (we, } \\
\text { us, our) }\end{array}$ & 23 & $1.25 \%$ & 34 & $1.68 \%$ \\
\hline $\begin{array}{l}\text { Second } \\
\text { person (you, } \\
\text { your) }\end{array}$ & 67 & $3.65 \%$ & 87 & $4.31 \%$ \\
\hline $\begin{array}{l}\text { Third person } \\
\text { masculine } \\
\text { singular (he, } \\
\text { him, his) }\end{array}$ & 9 & $0.49 \%$ & 14 & $0.69 \%$ \\
\hline $\begin{array}{l}\text { Third person } \\
\text { feminine } \\
\text { singular } \\
\text { (she, her) }\end{array}$ & 0 & $0 \%$ & 14 & $0.69 \%$ \\
\hline $\begin{array}{l}\text { Total count } \\
\text { of third } \\
\text { person } \\
\text { singular } \\
\text { (masculine } \\
\text { and } \\
\text { feminine) }\end{array}$ & 9 & $1.42 \%$ & 18 & $0.89 \%$ \\
\hline $\begin{array}{l}\text { Third person } \\
\text { plural (they, } \\
\text { them, their) }\end{array}$ & 26 & $0.49 \%$ & 28 & \\
\hline
\end{tabular}

According to the above table, men are shown to use slightly more first person singular pronouns to refer to themselves, while women use slightly more first person plural pronouns, second and third person singular pronouns. This implies that men are more concerned with their self-presentation than with involving themselves with others, unlike women who seem to be more likely to engage in social relationships and show intimacy, which agrees with the first hypothesis posed by this research. The use of self reference also serves to portray certain 
identity traits of each status writer. In the statuses where the male Facebook users refer to personal experiences or traits (shown in Table 1), 11 out of the 24 users $(46 \%)$ mention personal traits implying power, authority and independence. For example, they use statements such as "I am the master of my fate; I am the captain of my soul", "It was a respect for myself indeed", "Ask me about what I am able to do and see how genius I am", "I want my world to be fun. No parents, no rules, no nothing, like no one can stop me", and "I'm not a backup or an option. I'm a first choice."

On the other hand, the females' use of direct description of identity and personality traits is scarce as none of the 14 females who discuss personal experiences and traits gives a direct description of herself, but they rather express how they wish to be or what they aspire for. Their statuses include sentences such as "I support freedom of choice; I support women empowerment", and "I want to be a good model, and I want to be good with words. I want to be so smart and I want to have you forever". Even, when some of the female users mention personal achievement, they attribute such achievement to the efforts of other people or factors as in "Because of my friend, I had the courage to cut more than $25 \mathrm{~cm}$ of my hair to donate it to [a charity organization]" and "I believe and hope that through it all [the years I spent at university] came out a different person, hopefully a better one." In most of the above examples of male and female statuses about personal experiences, males portray themselves as powerful, independent and rebellious whereas females portray desired identities or identities they wish they could have rather than existing identities. This finding supports the second hypothesis that men use language showing authority and assertiveness, while women's language shows tentativeness.

In terms of the first person plural pronouns used by male and female subjects, Table 4 above shows that females use more first person plural pronouns such as "we, us and our" than males do. Yet, though males also use first person plural pronouns, they mainly use them to make general or sarcastic statements that describe general circumstances as in "We don't need to say anything in April Fool's Day because we are already living it" and "It's a mistake we never learn from." On the other hand, females' use of first person plural pronouns usually shows their involvement with others and their appreciation of social relationships as in "We complete everything together" and "We protect each other like brother and sister." This finding implies that females value social relationships and involvement with others more than males do.

Females also use slightly more second person pronouns such as "you" and "your" than males do; yet, it is the way each gender uses these pronouns rather than the word count that shows significant differences between males and females. Males use second person pronouns mainly to give advice to general 
readers rather than to address a specific person on their list as in "Stop worrying; you won't live forever any way," and "Be careful of who turn their back on you easily." Females, on the other hand, use second person pronouns mainly to address specific people as in "You guys made my day," and "I just want to tell you how special you are to me." This again implies females' tendency to show more involvement with others and maintain closer social relationships.

The use of first person plural pronouns and second person pronouns serves as an engagement strategy aiming to bring the writer and reader closer to each other. The use of first person plural pronouns (we, us and our) represents a way of including the reader and involving both the writer and reader in the same experience, which suggests women's concern with intimacy and maintaining close relationships. The employment of first person plural pronouns is often considered by discourse analysts as a positive politeness strategy (Brown and Levinson, 1987), which creates a sense of solidarity between the writer and the reader by establishing a common ground (Vasquez, 2014). The use of first person plural pronoun in the female posts to show politeness and maintain intimacy is supported by the finding of Arnold and Miller (1999) that women tended to be more sociable and friendly while men portrayed themselves as confident and independent. The same premise is supported by other research findings which suggest that women's online behavior is more interpersonallyoriented showing interaction and relationship maintenance, while men's online behavior is more individual and information-oriented (Parkins, 2012). Second person pronouns can also be used to increase involvement and engagement with the readers. Vasquez (2014) claims that the use of second person pronouns (you and your) is the most obvious and common linguistic feature associated with involvement and engagement strategies in online texts. Through their use of second person pronouns, females directly address the reader, who is usually a specific person (or specific people) on their lists, indicating concern for the reader's welfare or satisfaction.

In terms of third person pronouns, females show more tendency to refer to the single third person pronouns "he", "him", "his", "she", and her" with lexical density of $1.38 \%$ in female posts compared to $0.49 \%$ in male posts as shown in Table 4 above. On the other hand, males show more tendency to refer to the plural pronouns "they", "their" and "them" (with lexical density of $1.42 \%$ in male posts compared to $0.89 \%$ in female posts). This suggests that women are concerned with details and with addressing each individual with the relevant pronoun while men are more concerned with the general population. Also, the fact that the feminine third person singular pronouns (she, her) did not occur in any of the male posts is attributed to the finding made in section 2.1 above that males did not make any reference to female acquaintances. 


\subsection{Hedging devices}

The hedging devices used in the selected Facebook statuses fall into four main categories: tentative expressions such as "it seems possible that..." and "it appears that...", hypothetical situations such as "imagine if you had ....", modals suggesting uncertainty such as "could," "might," "maybe," and question tags like "you believe it, don't you?" The following table shows the word count and density (shown by percentage) of each hedging device in statuses of both genders.

Table 5 Word count of hedging devices in statuses of both genders

\begin{tabular}{|l|l|l|l|l|}
\hline Hedging devices & $\begin{array}{l}\text { Word Count } \\
\text { in Male } \\
\text { Statuses } \\
\mathrm{N}=1835\end{array}$ & Percentage & $\begin{array}{l}\text { Word Count } \\
\text { in Female } \\
\text { Statuses } \\
\mathrm{N}=2018\end{array}$ & Percentage \\
\hline $\begin{array}{l}\text { Tentative } \\
\text { expressions }\end{array}$ & 4 & $0.22 \%$ & 7 & $0.35 \%$ \\
\hline Modals & 17 & $0.93 \%$ & 14 & $0.69 \%$ \\
\hline $\begin{array}{l}\text { Hypothetical } \\
\text { situations }\end{array}$ & 3 & $0.16 \%$ & 9 & $0.45 \%$ \\
\hline Question tags & 0 & $0 \%$ & 2 & $0.10 \%$ \\
\hline
\end{tabular}

The females generally use more hedging devices than the males, that is, a total of 32 hedging devices in comparison to 24 . The females use more tentative expressions and more reference to hypothetical situations in order to mitigate the force of their statements, which may imply a sense of uncertainty and lack of confidence according to Lakoff (1975), but it may also be a sign of cooperative speech as suggested by Cameron, McAlinden \& O'Leary (1989) and Goodwin (1980) who all refuted Lakoff's claims as contentious and lacking empirical evidence. Cameron et al. (1989) believe that women use the so-called tentative features mentioned by Lakoff to facilitate conversation and show politeness rather than uncertainty. Similarly, Goodwin (1980) maintains that women use less mitigating utterances, not because they are less certain or powerful than men, but rather because of the different structures of male and female single-sex groups. Male groups are organized as hierarchical structures where members seek power and leadership, whereas female groups are organized along different 
lines where members tend to be more cooperative and maintain stronger social bonds (Goodwin, 1980). The results shown in Table 5 above support the second hypothesis that men use language showing authority and assertiveness, while women's language shows tentativeness, but tentativeness here is viewed in the light of the findings of Cameron et al. (1989) and Goodwin (1980) suggesting that women's mitigation of sentence force shows solidarity and politeness rather than lack of confidence.

\subsection{Boosting devices}

Boosting devices are linguistic devices that boost or intensify a speaker's proposition. The boosting devices found in the sample posts can be divided in three types: degree modifiers such as "so", "just", "very" and "too", intensifying adverbs such as "really," "definitely," "genuinely," "absolutely," "actually" and "always", and intensifying adjectives such as "awesome," "sure" and "amazing." The following table shows the word count and density (shown by percentage) of each boosting device in statuses of both genders.

Table 6 Frequency of boosting devices in statuses of both genders

\begin{tabular}{|l|l|l|l|l|}
\hline $\begin{array}{l}\text { Boosting } \\
\text { Device }\end{array}$ & $\begin{array}{l}\text { Frequency in } \\
\text { Male Statuses }\end{array}$ & Percentage & $\begin{array}{l}\text { Frequency in } \\
\text { Female } \\
\text { Statuses } \\
\mathrm{N}=2018\end{array}$ & Percentage \\
\hline $\begin{array}{l}\text { Degree } \\
\text { Modifiers }\end{array}$ & 14 & $0.76 \%$ & 29 & $1.44 \%$ \\
\hline $\begin{array}{l}\text { Intensifying } \\
\text { adverbs }\end{array}$ & 12 & $0.65 \%$ & 28 & $1.39 \%$ \\
\hline $\begin{array}{l}\text { Intensifying } \\
\text { adjectives }\end{array}$ & 5 & $0.27 \%$ & 6 & $0.29 \%$ \\
\hline
\end{tabular}

The above table shows that females tend to use more boosters such as degree modifiers and intensifying adverbs than males to give more emphasis to their statements. Examples of females' use of such devices include "I just want to thank you for your presence in my life. You have been always my backbone and great supporters in my life" and "I just enjoyed spending time with you.. you really care and you're a great supporter." The males in general use less degree modifiers than females, but show more tendency to use the modifier "too" than 
modifiers such as "very" and "so" as in "The number of people who unfriended me is too damn high" and "I still hear your words every time I am down or too stressed". One explanation could be that the intensifier 'too' implies a negative sentiment while 'very' and 'so' imply a positive one (Frej \& Nam, 2014). This finding supports previous research which found female comments on Facebook to contain more positive emotion words than male comments (Thelwall et al., 2009).

Lakoff (1975) argued that both hedging and boosting devices are considered evidence of an unconfident speaker. While hedging devices explicitly signal lack of confidence, boosting devices express the speaker's assumption that the addressee may remain unconvinced and therefore provide extra reassurance. According to this view, the tendency of the females to use more hedging and boosting devices than males indicates women's tentativeness. However, one cannot assume that all hedging and boosting devices show tentativeness or uncertainty as they may simply be used as positive politeness techniques to mitigate the force of statements and achieve solidarity among community members (Holmes, 2008).

\subsection{Adjectives and adverbs}

Evaluation of personal stance can be expressed using a variety of linguistic devices, the most common of which are evaluative adjectives and adverbs. All the adjectives and adverbs used in the sample status posts are counted and divided into positive ones such as "amazing" and "genuinely," negative ones such as "horrible" and "unfortunately," and neutral ones such as "endless" and "generally." The following table shows the number of occurrences of each type of adjective and adverb in the statuses made by both genders and the lexical density of each (shown by percentage).

Table 7 Number and percentage of occurrences of adjectives and adverbs in statuses of both genders

\begin{tabular}{|l|l|l|l|l|}
\hline Adjectives & $\begin{array}{l}\text { Number of } \\
\text { occurrences in } \\
\text { male statuses } \\
(\mathrm{N}=1835)\end{array}$ & $\begin{array}{l}\text { Pumber orcentage } \\
\text { occurrences in } \\
\text { female } \\
\text { statuses } \\
(\mathrm{N}=2018)\end{array}$ & Percentage \\
\hline Positive & 55 & $3.00 \%$ & 102 & $5.05 \%$ \\
\hline Negative & 19 & $1.04 \%$ & 19 & $0.94 \%$ \\
\hline Neutral & 10 & $0.55 \%$ & 32 & $1.59 \%$ \\
\hline
\end{tabular}




\begin{tabular}{|l|l|l|l|l|}
\hline Adverbs & $\begin{array}{l}\text { Number of } \\
\text { occurrences in } \\
\text { male statuses } \\
(\mathrm{N}=1835)\end{array}$ & Percentage & $\begin{array}{l}\text { Number of } \\
\text { occurrences in } \\
\text { female statuses } \\
(\mathrm{N}=2018)\end{array}$ & Percentage \\
\hline Positive & 12 & $0.65 \%$ & 25 & $1.24 \%$ \\
\hline Negative & 20 & $1.09 \%$ & 1 & $0.05 \%$ \\
\hline Neutral & 1 & $0.05 \%$ & 38 & $1.88 \%$ \\
\hline
\end{tabular}

The above numbers show a significantly higher tendency by females to use adjectives and adverbs to create a more evaluative discourse. The females outnumber the males in the use of adjectives and adverbs with positive sentiment (5.05\% positive adjectives and $1.24 \%$ positive adverbs mentioned by females compared to $3.00 \%$ positive adjectives and $0.65 \%$ positive adverbs mentioned by males) while the males use more negative adjectives and adverbs than females do $(1.04 \%$ and $1.09 \%$ compared to $0.94 \%$ and $0.05 \%$ respectively). This finding agrees with Thelwall et al. (2009) who found that female comments on Facebook contained more positive emotion words than male comments.

The above data analysis of the 100 status posts made by Egyptian young adults highlights inherent traits of male and female language choices in online settings and the implications these traits may have on the construction of gender identity. The findings of the present research address the two research questions posed at the beginning; that is, 'What are the topics discussed in Egyptian males' and females' Facebook status posts?' and 'What are the linguistic stance features and engagement strategies used by each gender to express particular attitudes?" The data analysis carried out suggests that the topics preferred by female Egyptian Facebook users are mainly those related to social relationships and experiences, while male Egyptian Facebook users prefer to discuss topics related to individual experiences and to giving advice. As for the linguistic features used by each gender to express particular attitudes in Facebook statuses, females are found to use more first person plural pronouns and second person pronouns to engage with their readers and maintain solidarity, whereas the males prefer the use of first person singular pronouns to reflect on personal experiences. Also, females are shown to use more hedging and boosting devices signaling mitigation of sentence force, as well as more evaluative adjectives and adverbs implying more concern with the emotional and affective content of language.

The above findings support the two hypotheses set at the beginning of the study according to findings of a large body of literature on gendered online communication. The results of the study validate the first hypothesis maintaining that men post more about facts, entertainment and individual experiences, while 
women post more about feelings, social relationships and activities involving others. This is evident in the analysis of the topics discussed in the sample status posts. The results also validate the second hypothesis stating that women's language is characterized by the use of features showing tentativeness; yet, these features also serve the purpose of complying with positive politeness strategies, which is one way that helps women maintain solidarity and strong social relationships.

\section{Conclusion}

The present study fills a gap in the research on gender identity in online settings, especially in regards to the Egyptian culture. The results of the study support previous research that has been done in the area of gender language differences in both online and offline communication settings in terms of the topics of interest preferred by each gender as well as the stance features and engagement strategies used by each. The data analysis of the Facebook status posts made by 50 male Egyptian FB users and 50 female Egyptian FB users reveals that male users prefer to discuss topics related to personal and individual experiences while females prefer to talk about relationships and social experiences. In terms of linguistic stance features and engagement strategies, males showed more self-centered attitudes while females showed more involvement with others and inclination towards positive politeness strategies that foster social solidarity. The data analysis also highlights how each gender constructs its online identity. Males prefer to portray themselves as powerful, assertive and independent whereas females tend to portray themselves as sensitive individuals who greatly value social connections and solidarity. Also, males' avoidance of mentioning female relatives on Facebook reflects the influence of cultural norms on their gender identity as the Egyptian culture shows tendency to hide female relations from public life as one way of experiencing male protection and supremacy. In fact, the present research implies that an individual's identity is continuously shaped and reshaped by the surrounding social, cultural and technological environments, which makes it inevitable to continuously study the process of identity construction across different cultures and time spans.

\section{References}

Arnold, J., \& Miller, H. (1999). Gender and Web Home Pages. Paper presented at the CAL99 Virtuality in Education Conference, London, March 28-31. Retrieved from http://ess.ntu.ac.uk/miller/ cyberpsych/cal99.htm. 
Besnier, N. (1990). Language and affect. Annual Review of Anthropology, 19, 419-451.

Bolander, B. \& Locher, M.A. (2010). Constructing identity on Facebook: Report on a pilot study. In Karen Junod and Didier Maillat (eds). Performing the self. Swiss Papers in English Language and Literature, 24, 165-85.

Bond, B. J. (2009). He posted, she posted: Gender differences in self-disclosure on social network sites. Rocky Mountain Communication Review, 6(2), 2937.

Boyd, D.M., \& Ellison, N. B. (2007). Social network sites: Definition, history, and scholarship. Journal of Computer-Mediated Communication, 13(1), article 11.

Brown P. \& Levinson, S.C. (1987). Politeness: Some universals in language use. Cambridge, UK: Cambridge University Press.

Burman, E., \& Parker, I. (1993). Discourse Analytic Research: Repertoires and Readings of Texts in Action. London: Routledge.

Butler, J. (1990). Gender Trouble: Feminism and the Subversion of Identity. New York: Routledge.

Cameron, D., McAlinden, F. \& O'Leary, K. (1989). The social and linguistic features of tag questions. In Jennifer Coates \& Deborah Cameron (eds). Women in their speech communities. New York: Longman, pp. 74-93.

Crystal, D. (2001). Language and the Internet. Cambridge : Cambridge University Press.

DeAndrea, D., Shaw, A., \& Levine, T. (2009). Culture and self-expression in online social networking: An examination of self-construals on facebook. Conference Papers -- International Communication Association, 1-22.

Deaux, K., \& Major, B. (1987). Putting gender into context: An interactive model of gender-related behavior. Psychological Review, 94, 369-389.

Eagly, A.H. (1987). Sex differences in social behavior: A social-role interpretation. Erlbaum, Hillsdale, NJ.

Eckert, P. 2008. Variation and the indexical field. Journal of Sociolinguistics, $12,453-476$.

Eisenlauer, V. (2013). A critical hypertext analysis of social media: The true colors of Facebook. London: Bloomsbury.

Fogel, J. \& Nehmad, E. (2009). Internet social network communities: Risk taking, trust, and privacy concerns. Computers in Human Behavior, 25, 153160

Foster, E.K. (2004). Research on gossip: Taxonomy, methods and future directions. Review of General Psychology, 8, 78-99.

Fowler, R., Hodge, B., Kress, G. \& Trew, T. (1979). Language and Control. London, Routledge. 
Frej, M.Y. \& Nam, J. (2014). Study on the Sentiment Polarity Types of Collocations for too and very. Athens Journal of Philology, 1 (1), 23-32.

Glad. (2011). In The American Heritage Dictionary of the English Language, Fifth Edition. Retrieved from https://www.thefreedictionary.com/glad

Goodwin, M. (1980). Directive-response speech sequences in girls' and boys' task activities. In Sally McConnell Ginell, Ruth Borker \& Nelly Furman (eds). Women and language in literature and society. New York: Praeger, pp. 157-73.

Graddol, D., \& Swann, J. (1989). Gender Voices. London: Basil Blackwell.

Hargittai, E. (2008). Whose space? Differences among users and non-users of social network sites. Journal of Computer-Mediated Communication, 13, 276-297. Retrieved from http://onlinelibrary.wiley.com/doi/ 10.1111/j.10836101.2007.00396.x/pdf

Harter, S. (1998). The development of self-representations. In W.Damon \& N.Eisenberg (Eds.), Handbook of Child Psychology: Social, Emotional, and Personality Development. New York: Wiley, 553-617.

Herring, S. C. (2000). Gender differences in CMC: Findings and implications. Computer Professionals for Social Responsibility Journal, 18 (1). Retrieved from http://archive.cpsr.net/publications/ newsletters/issues/2000/winter2000/herring.html.

Holmes, J. (2008). An introduction to sociolinguistics. London: Pearson.

Hudson, M.B., Nicolas, S.C., Howser, M.E., Lipsett, K.E., Robinson, I.W., Pope, L.J., Hobby, A.F. \& Friedman, D.R. (2015). Examining How Gender and Emoticons Influence Facebook Jealousy. Cyberpsychology, Behavior, and Social Networking, 18 (2), 87-92.

Huffaker, D.A. \& Calvert, S.L. (2006). Gender, identity and language use in teenage blogs. Journal of computer-mediated communication, 10(2).

Hyland, K. (2005). Stance and engagement: A model of interaction in academic discourse. Discourse Studies, 7, 173-92.

Joiner, R., Dapkeviciute, L., Johnson, H., Gavin, J. \& Brosnan, M. (2015). Two studies investigating gender differences in response to facebook status updates. Proceedings of the Ninth International AAAI Conference on Web and Social Media. Retrieved from https://www.aaai.org/ocs/ index.php/ICWSM/ICWSM15/paper/view/10497/10458

Kelly, J. R., \& Hutson-Comeaux, S. L. (1999). Gender-Emotion Stereotypes are context specific. Sex Roles, 40(1/2), 107-120.

Klimanova, L. (2013). Second language identity building through participation in internet-mediated environments: a critical perspective. Iowa Research Online. Retrieved from http://ir.iowa.edu/etd/5001 
Kramer, N.C. \& Winter, S. (2008). The relationship of self-esteem, extraversion, self-efficacy, and self-presentation within social networking sites. Journal of Media Psychology, 20(3), 106-116.

Lakoff, R. (1975). Language and women's place. New York: Harper \& Row.

Lee, E.J. (2008). Mediated Social Interaction. The International Encyclopedia of Communication. Wiley Online Library.

DOI: 10.1002/9781405186407.wbiecm058

Lemish, D. (2008). Gender: Representation in the Media. The International Encyclopedia of Communication. Wiley Online Library.

DOI: $10.1002 / 9781405186407 . w b i e c g 008$

Lury,C. (1995). The Rights and Wrongs of Culture: Issues of Theory and Methodology. In B. Skegges (ed.), Feminist Cultural Theory: Process and Production. Manchester: Manchester University Press.

Muscanell, N. L., \& Guadagno, R. E. (2012). Make new friends or keep the old: Gender and personality differences in social networking use. Computers in Human Behavior, 28(1), 107-112.

Naughton, J. (1999). A Brief History of the Future: The Origins of the Internet. London: Weidenfield and Nicolson.

Park, J. 2007. Interpersonal and Affective Communication in Synchronous Online Discourse. The Library Quarterly 77, 133-155.

Parkins, R. (2012). Gender and Emotional Expressiveness: An Analysis of Prosodic Features in Emotional Expression . Griffith Working Papers in Pragmatics and Intercultural Communication 5 (1), 46-54.

Ruiz, J. (2009). Sociological discourse analysis: methods and logic. Qualitative Social Research, 10(2), Art. 26. Retrieved from

http://nbn-resolving.de/urn:nbn:de:0114-fqs0902263

Savicki, V. (1996). Gender language style and group composition in internet discussion groups. Journal of Computer-Mediated Communication, 2 (3). Retrieved from $\mathrm{http}: / / \mathrm{jcmc}$.indiana.edu/vol2/issue3/savicki.html

Shalghin, A. (2017). Toward Understanding Arab Women's Cultural Landscapes. International Journal of Comparative Literature \& Translation Studies, 5(2), 14-18.

Tannen, D. (1990). You just don't understand: Men and women in conversation. New York: Ballantine

Thelwall, M., Wilkinson, D., \& Uppal, S. (2009). Data mining emotion in social network communication: Gender differences in MySpace. Journal of the American Society for Information Science and Technology, 61(1): 190-199.

Thompson, S. H., \& Lougheed, E. (2012). Frazzled by Facebook? An exploratory study of gender differences in social network communication 
among undergraduate men and women. College Student Journal, 46(1), 8898.

Tong, S.T., Van Der Heide, B., Langwell, L. \& Walther, J.B. (2008). Too much of a good thing? The relationship between number of friends and interpersonal impressions on Facebook. Journal of Computer-Mediated Communication, 13, 531-549.

Turkle, S. (1995). Life on the screen: Identity in the age of the Internet. New York: Simon \& Schuster.

Vasquez, C. (2014). The discourse of online consumer reviews. London: Bloomsbury.

Walker, K.L. (2015). Women's Communication and Language. The International Encyclopedia of Communication. Wiley Online Library. DOI: 10.1002/9781405186407.wbiecw007.pub3

Weatherall, A. (2008). Gender and Discourse. The International Encyclopedia of Communication. Wiley Online Library.

DOI: 10.1002/9781405186407.wbiecg005 